\title{
ANALISIS PERPIDAHAN PENGGUNAAN MEREK SIMCARD DENGAN PENDEKATAN RANTAI MARKOV
}

\author{
Nurma Aliyuwaningsih $^{1 \S}$, I Wayan Sumarjaya ${ }^{2}$, I Gusti Ayu Made Srinadi ${ }^{3}$ \\ ${ }^{1}$ Program Studi Matematika, Fakultas MIPA - UniversitasUdayana [Email: email: ichy43@gmail.com] \\ ${ }^{2}$ Program Studi Matematika, Fakultas MIPA - UniversitasUdayana [Email: sumarjaya@ unud.ac.id] \\ ${ }^{3}$ Program Studi Matematika, Fakultas MIPA - UniversitasUdayana [Email: srinadi@unud.ac.id] \\ ${ }^{\S}$ Corresponding Author
}

\begin{abstract}
The aim of this research is to know the displacement made by consumers of GSM cards and predictions of market share when reaching equilibrium conditions for each of the displacements made by consumers of GSM cards. This research uses Markov chain method. Markov chain method produces probabilistic information that can be used to assist for making decision. In Markov's analysis, the equilibrium conditions are conditions in which the variables in the system ultimately bring the transition probabilities in stable or unchanged conditions. Data from this research is divided into two categories namely data about brand switching of GSM cards and data about the transfer of GSM cards brand usage. Data brand switching of GSM cards obtained from users who use one GSM cards, while the data transfer use of GSM cards obtained from user more than one GSM cards. The results of this research indicate that GSM card displacement equilibrium conditions was achieved in the $9^{\text {th }}$ period, whereas the results of switching the use of GSM card shows that equilibrium conditions for phone and SMS users is in the $15^{\text {th }}$ period, and equilibrium conditions for internet user is reached in $5^{\text {th }}$ period.
\end{abstract}

Keywords: Markov Chain, Equilibrium Conditions

\section{PENDAHULUAN}

Konsep rantai Markov dikembangkan oleh seorang matematikawan Rusia bernama Andrey A. Markov pada tahun 1906. Rantai Markov adalah suatu teknik matematika yang biasa digunakan untuk melakukan pembuatan model (modelling) bermacam-macam sistem dan proses bisnis. Teknik rantai Markov dapat digunakan untuk meramalkan perubahan-perubahan pada waktu yang akan datang dalam variabelvariabel dinamis berdasarkan hasil pengamatan pada variabel-variabel tersebut pada masa yang lalu. Teknik ini dapat juga digunakan untuk menganalisis kejadian-kejadian pada waktuwaktu mendatang secara matematis (Subagyo dkk., 1999).

Analisis rantai Markov menghasilkan suatu informasi probabilistik yang dapat digunakan untuk membantu pembuatan keputusan, sehingga analisis ini bukan suatu teknik optimisasi melainkan suatu teknik deskriptif. Analisis Markov merupakan suatu bentuk khusus dari model probabilistik yang lebih umum yang dinamakan proses stokastik (Aswin, 2010).

Sebagai suatu peralatan riset operasi dalam pengambilan keputusan manajerial, rantai Markov telah banyak diterapkan untuk menganalisis tentang perpindahan merek (brand switching) dalam pemasaran, perhitungan rekening-rekening, jasa-jasa penyewaan mobil, perencanaan penjualan, masalah-masalah persediaan, antrian, perubahan harga pasar saham, dan administrasi rumah sakit (Subagyo dkk., 1999).

Dengan semakin meningkatnya penggunaan handphone, maka para provider berlomba-lomba untuk mendapatkan pelanggan agar dapat 
menguasai pangsa pasar kartu GSM (Global System for Mobile Comunication). Untuk memaksimalkan pengambilan keputusan periode mendatang, suatu provider atau perusahaan telekomunikasi dapat melakukan prediksi pangsa pasar untuk periode mendatang.

Tujuan dari penelitian ini adalah untuk memodelkan perpindahan yang dilakukan oleh konsumen dibedakan menjadi dua yaitu (1) pengguna satu kartu GSM dan (2) pengguna dua kartu GSM dengan menggunakan analisis rantai Markov serta untuk memprediksi pangsa pasar saat mencapai kondisi ekuilibrium (steady state) untuk masing-masing perpindahan yang dilakukan konsumen.

\section{METODE PENELITIAN}

\section{A. Metode Pengumpulan Data}

Data pada penelitian ini diperoleh dengan menyebarkan kuesioner kepada 180 orang mahasiswa Fakultas MIPA Universitas Udayana. Penelitian ini menggunakan teknik pengambilan sampel accidental sampling.

Sebelum disebarluaskan, terlebih dahulu kuesioner diuji validitas dan reliabilitasnya. Pengujian validitas dan reliabilitas dilakukan saat sampel berjumlah 30 .

\section{B. Metode Analisis Data}

Langkah-langkah analisis rantai Markov untuk menghitung peluang perpindahan merek dan perpindahan penggunaan merek kartu GSM serta pangsa pasar saat mencapai kondisi ekuilibrium: (1) menghitung jumlah pelanggan masing-masing merek pada periode ke- 0 dan jumlah pada periode ke-1; (2) menghitung perubahan merek dalam kurun waktu satu tahun; (3) menyusun matriks probabilitas transisi yang digunakan untuk menggambarkan rantai Markov tentang kegiatan pemilihan merek dan peramalan probabilitas transisi yang kemungkinan dilakukan oleh para konsumen; (4) Membuat matriks probabilitas transisi berukuran $(n \times n)$ dari merek-merek kartu prabayar GSM yang digunakan responden; (5) Menghitung kemungkinan pangsa pasar pada waktu mendatang; (6) Menentukan kondisi ekuilibrium (steady state).

\section{HASIL DAN PEMBAHASAN}

\section{A. Profil Responden}

Profil responden dalam penelitian ini ditinjau dari jenis kelamin, usia, dan program studi yang ditampilkan pada Tabel 1 berikut:

Tabel 1. Profil Responden

\begin{tabular}{|c|c|c|c|}
\hline \multicolumn{2}{|c|}{ Deskripsi responden } & Jumlah & Persentase \\
\hline \multirow{4}{*}{$\begin{array}{c}\text { Jenis } \\
\text { kelamin }\end{array}$} & Laki-laki & 68 & $38 \%$ \\
\cline { 2 - 4 } & perempuan & 112 & $62 \%$ \\
\hline \multirow{4}{*}{ Usia } & $16-18$ & 42 & $23 \%$ \\
\cline { 2 - 4 } & $19-21$ & 115 & $64 \%$ \\
\cline { 2 - 4 } & $22-24$ & 23 & $13 \%$ \\
\hline \multirow{4}{*}{\begin{tabular}{c} 
Program Studi \\
\cline { 2 - 4 }
\end{tabular}} & Biologi & 19 & $10 \%$ \\
\cline { 2 - 4 } & Kimia & 28 & $16 \%$ \\
\cline { 2 - 4 } & Fisika & 48 & $27 \%$ \\
\cline { 2 - 4 } & $\begin{array}{c}\text { Ilmu } \\
\text { Komputer }\end{array}$ & 31 & $13 \%$ \\
\cline { 2 - 4 } & Farmasi & 30 & $17 \%$ \\
\hline
\end{tabular}

Sumber Data Primer: Diolah 2017

\section{B. Analisis Rantai Markov}

Suatu proses stokastik $\left\{X_{t}, t=0,1, \ldots\right\}$ dengan waktu diskret dikatakan sebagai rantai Markov, jika untuk sebarang periode $t=$ $0,1,2, \ldots$ dan untuk semua kondisi /state, berlaku sifat khusus rantai Markov yaitu (Surachman dan Astuti, 2015):

$\operatorname{Pr}\left\{X_{t+1}=j \mid X_{0}=i_{0}, \ldots, X_{t-1}=i_{t-1}, X_{t}=i\right\}=$ $\operatorname{Pr}\left\{X_{t+1}=j \mid X_{t}=i\right\}$.

Untuk dapat menerapkan analisis rantai Markov ke dalam suatu kasus, ada beberapa syarat yang harus dipenuhi (Yakub, 2008):

1) Jumlah probabilitas transisi untuk suatu keadaan awal dari sistem sama dengan 1 .

2) Probabilitas transisi konstan sepanjang waktu, artinya peluang untuk setiap keadaan periode $t \geq 0$ adalah sama.

3) Probabilitas transisi hanya tergantung pada status sekarang, bukan pada periode sebelumnya.

Metode yang digunakan dalam penelitian ini yaitu dengan menggunakan metode rantai Markov. Pertama, menyusun data perpidahan 
merek; menyusun matriks probabilitas trannsisi; dan menghitung pangsa pasar saat mencapai kondisi ekuilibrium.

\section{Data Perpindahan Kartu GSM}

Data yang diperoleh dari penelitian ini dibagi menjadi dua kategori yaitu data tentang perpindahan merek simcard dan data perpindahan penggunaan merek simcard. Data perpindahan merek simcard didapat dari responden yang menggunakan satu kartu GSM dengan jumlah responden sebanyak 83 orang, sedangkan data perpindahan penggunaan merek simcard berasal dari responden yang menggunakan lebih dari satu kartu GSM dengan jumlah responden sebanyak 97 orang.

Dalam kasus ini pada responden yang menggunakan lebih dari satu kartu GSM akan dihitung matriks probabilitas transisi perpindahan penggunaan Telepon dan SMS serta perpindahan penggunaan internet. Berikut adalah data pergantian dari kartu GSM:

\section{Data Pengguna Satu Kartu GSM}

Data yang diperoleh dari penelitian ini dibagi menjadi dua kategori yaitu data tentang perpindahan merek simcard dan data perpindahan penggunaan merek simcard.

Tabel 2. Daya Mendapatkan-Kehilangan bagi Pengguna Satu Kartu GSM

\begin{tabular}{|c|c|c|c|c|}
\hline Merek & $\begin{array}{c}\text { Periode } \\
\text { ke-0 }\end{array}$ & Mendapatkan & Kehilangan & $\begin{array}{c}\text { Periode } \\
\text { ke-1 }\end{array}$ \\
\hline A & 12 & 7 & 8 & 11 \\
\hline B & 24 & 16 & 13 & 27 \\
\hline C & 15 & 7 & 12 & 10 \\
\hline D & 19 & 9 & 13 & 15 \\
\hline E & 3 & 0 & 3 & 0 \\
\hline F & 8 & 4 & 5 & 7 \\
\hline G & 2 & 13 & 2 & 13 \\
\hline Total & $\mathbf{8 3}$ & $\mathbf{5 6}$ & $\mathbf{5 6}$ & $\mathbf{8 3}$ \\
\hline
\end{tabular}

Sumber Data Primer; Diolah 2017

Keterangan: $\mathrm{A}=\mathrm{As} ; \mathrm{B}=$ Simpati; $\mathrm{C}=\mathrm{XL} ; \mathrm{D}=\mathrm{IM} 3$; $\mathrm{E}=$ Mentari; $\mathrm{F}=$ Three; $\mathrm{G}=\mathrm{AXIS}$

Berdasarkan Tabel 2 dari ketujuh kartu GSM, kartu GSM yang mendapatkan pelanggan terbesar dari kartu GSM lain adalah kartu GSM Simpati. Kartu GSM Simpati menjadi kartu
GSM dengan jumlah kehilangan pelanggan terbesar bersama dengan kartu GSM IM3.

Berdasarkan Tabel 2 dapat diketahui bahwa peluang probabilitas awal untuk pengguna satu kartu GSM adalah sebagai berikut:

$X_{0}=\left[\frac{12}{83}, \frac{24}{83}, \frac{15}{83}, \frac{19}{83}, \frac{3}{83}, \frac{8}{83}, \frac{2}{83}\right]$

Tabel 3. Data Responden Pengguna Kartu GSM untuk Telepon dan SMS

\begin{tabular}{|c|c|c|c|c|}
\hline Merek & $\begin{array}{c}\text { Periode } \\
\text { ke-0 }\end{array}$ & Mendapatkan & Kehilangan & $\begin{array}{c}\text { Periode } \\
\text { ke-1 }\end{array}$ \\
\hline A & 27 & 13 & 17 & 23 \\
\hline B & 37 & 15 & 27 & 25 \\
\hline C & 9 & 7 & 6 & 10 \\
\hline D & 13 & 12 & 7 & 18 \\
\hline E & 4 & 2 & 4 & 2 \\
\hline F & 4 & 5 & 4 & 5 \\
\hline G & 3 & 12 & 1 & 14 \\
\hline Total & $\mathbf{9 7}$ & $\mathbf{6 6}$ & $\mathbf{6 6}$ & $\mathbf{9 7}$ \\
\hline
\end{tabular}

Sumber Data Primer; Diolah 2017

Keterangan: $\mathrm{A}=\mathrm{As} ; \mathrm{B}=$ Simpati; $\mathrm{C}=\mathrm{XL} ; \mathrm{D}=\mathrm{IM} 3$; $\mathrm{E}=$ Mentari; $\mathrm{F}=$ Three; $\mathrm{G}=\mathrm{AXIS}$

Berdasarkan Tabel 3 kartu GSM yang paling banyak mendapatkan pelanggan dari kartu GSM lain adalah kartu GSM Simpati, serta kartu GSM Simpati juga yang mengalami kehilangan terbesar.

Dari Tabel 3 dapat diketahui bahwa peluang probabilitas awal untuk penggunaan telepon dan SMS bagi pengguna dua kartu GSM adalah sebagai berikut:

$Y_{0}=\left[\frac{27}{97}, \frac{37}{97}, \frac{9}{97}, \frac{13}{97}, \frac{4}{97}, \frac{4}{97}, \frac{3}{97}\right]$

Tabel 4. Data Responden Pengguna Kartu GSM untuk Internet

\begin{tabular}{|c|c|c|c|c|}
\hline Merek & $\begin{array}{c}\text { Periode } \\
\text { ke-0 }\end{array}$ & Mendapatkan & Kehilangan & $\begin{array}{c}\text { Periode } \\
\text { ke-1 }\end{array}$ \\
\hline A & 27 & 1 & 24 & 4 \\
\hline B & 37 & 14 & 32 & 19 \\
\hline C & 9 & 22 & 7 & 24 \\
\hline D & 13 & 17 & 11 & 19 \\
\hline E & 4 & 0 & 4 & 0 \\
\hline F & 4 & 11 & 3 & 12 \\
\hline G & 3 & 19 & 3 & 19 \\
\hline Total & $\mathbf{9 7}$ & $\mathbf{6 6}$ & $\mathbf{6 6}$ & $\mathbf{9 7}$ \\
\hline
\end{tabular}

Sumber Data Primer; Diolah 2017

Keterangan: $\mathrm{A}=\mathrm{As} ; \mathrm{B}=$ Simpati; $\mathrm{C}=\mathrm{XL} ; \mathrm{D}=\mathrm{IM} 3$; $\mathrm{E}=$ Mentari; $\mathrm{F}=$ Three; $\mathrm{G}=\mathrm{AXIS}$ 
Dari Tabel 4 juga dapat dilihat bahwa kartu GSM XL mendapatkan pelanggan terbesar, dan kartu GSM yang mengalami kehilangan pelanggan terbesar adalah kartu GSM Simpati. Peluang probabilitas awal untuk penggunaan Internet bagi pengguna dua kartu GSM adalah sebagi berikut:

$Z_{0}=\left[\frac{27}{97}, \frac{37}{97}, \frac{9}{97}, \frac{13}{97}, \frac{4}{97}, \frac{4}{97}, \frac{3}{97}\right]$

\section{a Menyusun Matriks Probabilitas Transisi}

Proses Markov dalam penelitian ini dapat digunakan untuk mengetahui pemilihan kartu GSM untuk periode yang akan datang bergantung pada pemilihan kartu GSM pada satu periode sebelumnya. Selain itu, rantai Markov dapat juga digunakan untuk menentukan kondisi ekuilibrium (steady state) pada waktu mendatang. Hasil penelitian yang dilakukan memberikan informasi tentang pola perpindahan kartu GSM:

Tabel 5. Perpindahan Bagi Pengguna Satu Kartu GSM

\begin{tabular}{|c|c|c|c|c|c|c|c|c|}
\hline \multirow{2}{*}{ Mendapatkan } & \multicolumn{7}{|c|}{ Kehilangan } & \multirow{2}{*}{ Total } \\
\cline { 2 - 9 } & $\mathbf{A}$ & $\mathbf{B}$ & $\mathbf{C}$ & $\mathbf{D}$ & $\mathbf{E}$ & $\mathbf{F}$ & $\mathbf{G}$ & \\
\hline A & 4 & 1 & 3 & 1 & 0 & 1 & 1 & 11 \\
\hline B & 2 & 11 & 6 & 7 & 0 & 1 & 0 & 27 \\
\hline C & 3 & 0 & 3 & 1 & 2 & 1 & 0 & 10 \\
\hline D & 1 & 4 & 2 & 6 & 0 & 2 & 0 & 15 \\
\hline E & 0 & 0 & 0 & 0 & 0 & 0 & 0 & 0 \\
\hline F & 1 & 1 & 1 & 1 & 0 & 3 & 0 & 7 \\
\hline G & 1 & 7 & 0 & 3 & 1 & 0 & 1 & 13 \\
\hline
\end{tabular}

Sumber Data Primer; Diolah 2017

Keterangan: $\mathrm{A}=\mathrm{As} ; \mathrm{B}=$ Simpati; $\mathrm{C}=\mathrm{XL} ; \mathrm{D}=\mathrm{IM} 3$; $\mathrm{E}=$ Mentari; $\mathrm{F}=$ Three; $\mathrm{G}=\mathrm{AXIS}$

Berdasarkan Tabel 5, Selanjutnya, matriks probabilitas dan matriks probabilitas awal perpindahan bagi pengguna satu kartu GSM dituliskan dalam bentuk matriks transisi stokastik yang terlihat seperti di bawah ini:

$X:\left[\begin{array}{lllllll}0,333 & 0,042 & 0,200 & 0,053 & 0,000 & 0,125 & 0,500 \\ 0,167 & 0,458 & 0,400 & 0,368 & 0,000 & 0,125 & 0,000 \\ 0,250 & 0,000 & 0,200 & 0,053 & 0,667 & 0,125 & 0,000 \\ 0,083 & 0,167 & 0,133 & 0,316 & 0,000 & 0,250 & 0,000 \\ 0,000 & 0,000 & 0,000 & 0,000 & 0,000 & 0,000 & 0,000 \\ 0,083 & 0,042 & 0,067 & 0,053 & 0,000 & 0,375 & 0,000 \\ 0,083 & 0,292 & 0,000 & 0,158 & 0,333 & 0,000 & 0,500\end{array}\right]$

$X_{0}:\left[\begin{array}{lllllll}0,145 & 0,289 & 0,181 & 0,228 & 0,036 & 0,096 & 0,024\end{array}\right]$
Keterangan: $X$ adalah matriks probabilitas transisi bagi pengguna satu kartu GSM dan $X_{0}$ adalah matriks probabilitas awal bagi pengguna satu kartu GSM.

Tabel 6. Perpindahan Penggunaan Telepon dan SMS (Bagi Pengguna dua Kartu GSM)

\begin{tabular}{|c|c|c|c|c|c|c|c|c|}
\hline \multirow{2}{*}{ Mendapatkan } & \multicolumn{7}{|c|}{ Kehilangan } & \multirow{2}{*}{ Total } \\
\cline { 2 - 9 } & A & B & $\mathbf{C}$ & $\mathbf{D}$ & $\mathbf{E}$ & $\mathbf{F}$ & $\mathbf{G}$ & \\
\hline A & 10 & 9 & 2 & 0 & 0 & 1 & 1 & 23 \\
\hline B & 5 & 10 & 1 & 5 & 2 & 2 & 0 & 25 \\
\hline C & 1 & 4 & 3 & 1 & 0 & 1 & 0 & 10 \\
\hline D & 5 & 6 & 1 & 6 & 0 & 0 & 0 & 18 \\
\hline E & 1 & 1 & 0 & 0 & 0 & 0 & 0 & 2 \\
\hline F & 1 & 2 & 0 & 1 & 1 & 0 & 0 & 5 \\
\hline G & 4 & 5 & 2 & 0 & 1 & 0 & 2 & 14 \\
\hline
\end{tabular}

Sumber Data Primer; Diolah 2017

Keterangan: $\mathrm{A}=\mathrm{As} ; \mathrm{B}=$ Simpati; $\mathrm{C}=\mathrm{XL} ; \mathrm{D}=\mathrm{IM} 3$; $\mathrm{E}=$ Mentari; $\mathrm{F}=$ Three; $\mathrm{G}=\mathrm{AXIS}$

Berdasarkan Tabel 6, matriks probabilitas dan matriks probabilitas awal perpindahan bagi penggunaan telepon dan SMS dituliskan dalam bentuk matriks transisi stokastik yang terlihat seperti di bawah ini:

$Y:\left[\begin{array}{lllllll}0,370 & 0,243 & 0,222 & 0,000 & 0,000 & 0,250 & 0,333 \\ 0,185 & 0,270 & 0,111 & 0,384 & 0,500 & 0,500 & 0,000 \\ 0,037 & 0,108 & 0,333 & 0,076 & 0,000 & 0,250 & 0,000 \\ 0,185 & 0,162 & 0,111 & 0,461 & 0,000 & 0,000 & 0,000 \\ 0,037 & 0,027 & 0,000 & 0,000 & 0,000 & 0,000 & 0,000 \\ 0,037 & 0,054 & 0,000 & 0,076 & 0,250 & 0,000 & 0,000 \\ 0,148 & 0,135 & 0,222 & 0,000 & 0,250 & 0,000 & 0,667\end{array}\right]$
$Y_{0}:\left[\begin{array}{lllllll}0,278 & 0,381 & 0,092 & 0,134 & 0,041 & 0,041 & 0,031\end{array}\right]$

Keterangan: $Y$ adalah matriks probabilitas transisi bagi perpindahan penggunaan telepon dan SMS dan $Y_{0}$ adalah matriks probabilitas awal bagi penggunaan telepon dan SMS untuk pengguna dua kartu GSM.

Tabel 7. Perpindahan Penggunaan Internet (Bagi Pengguna dua Kartu GSM)

\begin{tabular}{|c|c|c|c|c|c|c|c|c|}
\hline \multirow{2}{*}{ Mendapatkan } & \multicolumn{7}{|c|}{ Tota } \\
\cline { 2 - 8 } & $\mathbf{A}$ & $\mathbf{B}$ & $\mathbf{C}$ & $\mathbf{D}$ & $\mathbf{E}$ & $\mathbf{F}$ & $\mathbf{G}$ & 1 \\
\hline A & 3 & 0 & 0 & 0 & 0 & 0 & 1 & 4 \\
\hline B & 7 & 5 & 3 & 3 & 0 & 1 & 0 & 19 \\
\hline C & 5 & 12 & 2 & 1 & 1 & 2 & 1 & 24 \\
\hline D & 5 & 9 & 1 & 2 & 2 & 0 & 0 & 19 \\
\hline E & 0 & 0 & 0 & 0 & 0 & 0 & 0 & 0 \\
\hline F & 3 & 4 & 1 & 1 & 1 & 1 & 1 & 12 \\
\hline G & 4 & 7 & 2 & 6 & 0 & 0 & 0 & 19 \\
\hline
\end{tabular}

Sumber Data Primer; Diolah 2017

Keterangan: $\mathrm{A}=\mathrm{As} ; \mathrm{B}=\mathrm{Simpati} \quad \mathrm{C}=\mathrm{XL} ; \mathrm{D}=\mathrm{IM} 3$; $\mathrm{E}=$ Mentari; $\mathrm{F}=$ Three; $\mathrm{G}=\mathrm{AXIS}$ 
Berdasarkan Tabel 7, matriks probabilitas dan matriks probabilitas awal perpindahan bagi penggunaan internet dituliskan dalam bentuk matriks transisi stokastik yang terlihat seperti di bawah ini:

$Z:\left[\begin{array}{lllllll}0,111 & 0,000 & 0,000 & 0,000 & 0,000 & 0,000 & 0,333 \\ 0,259 & 0,135 & 0,333 & 0,230 & 0,000 & 0,250 & 0,000 \\ 0,185 & 0,324 & 0,222 & 0,076 & 0,250 & 0,500 & 0,333 \\ 0,185 & 0,243 & 0,111 & 0,153 & 0,500 & 0,000 & 0,000 \\ 0,000 & 0,000 & 0,000 & 0,000 & 0,000 & 0,000 & 0,000 \\ 0,111 & 0,108 & 0,111 & 0,076 & 0,250 & 0,250 & 0,333 \\ 0,148 & 0,189 & 0,222 & 0,461 & 0,000 & 0,000 & 0,000\end{array}\right]$

$Z_{0}:\left[\begin{array}{lllllll}0,278 & 0,381 & 0,092 & 0,134 & 0,041 & 0,041 & 0,031\end{array}\right]$

Keterangan: $Z$ adalah matriks probabilitas transisi bagi perpindahan penggunaan internet dan $Z_{0}$ adalah matriks probabilitas awal bagi penggunaan internet untuk pengguna dua kartu GSM.

\section{b Analisis Pangsa Pasar untuk Waktu yang Akan Datang}

Untuk mengetahui probabilitas keadaan sistem pada waktu yang akan datang diperoleh dari hasil perkalian matriks probabilitas awal dengan matriks probabilitas transisi $n$ waktu. Probabilitas awal diperoleh dari total masingmasing pangsa pasar (market share) pada periode ke-0 dibagi dengan total keseluruhan pangsa pasar (market share) pada periode ke-0.

\section{Pangsa Pasar Pengguna Satu Kartu GSM}

pangsa pasar $=X \times X_{0}$
$\left[\begin{array}{lllllll}0,333 & 0,042 & 0,200 & 0,053 & 0,000 & 0,125 & 0,500 \\ 0,167 & 0,458 & 0,400 & 0,368 & 0,000 & 0,125 & 0,000 \\ 0,250 & 0,000 & 0,200 & 0,053 & 0,667 & 0,125 & 0,000 \\ 0,083 & 0,167 & 0,133 & 0,316 & 0,000 & 0,250 & 0,000 \\ 0,000 & 0,000 & 0,000 & 0,000 & 0,000 & 0,000 & 0,000 \\ 0,083 & 0,042 & 0,067 & 0,053 & 0,000 & 0,375 & 0,000 \\ 0,083 & 0,292 & 0,000 & 0,158 & 0,333 & 0,000 & 0,500\end{array}\right] \times$
$\left[\begin{array}{l}0,145 \\ 0,289 \\ 0,181 \\ 0,228 \\ 0,036 \\ 0,096 \\ 0,024\end{array}\right]=\left[\begin{array}{l}0,133 \\ 0,325 \\ 0,120 \\ 0,181 \\ 0,000 \\ 0,084 \\ 0,157\end{array}\right]$

Dari hasil perhitungan tersebut terlihat bahwa pada periode ke-1 kartu GSM Simpati menempati pangsa pasar tertinggi dengan persentase sebesar $31 \%$, posisi kedua ditempati oleh kartu GSM IM3 dengan persentase sebesar $18 \%$, posisi ketiga ditempati oleh kartu GSM Axis dengan persentase sebesar $16 \%$, diposisi keempat ditempati oleh kartu GSM As dengan persentase sebesar 13\%, posisi terakhir ditempati oleh kartu GSM Three dengan persentase sebesar $8 \%$.

Selanjutnya dengan cara yang sama untuk mendapatkan nilai probabilitas pangsa pasar saat mencapai steady state, di mana kondisi steady state akan terjadi jika matriks pangsa pasarnya tidak berubah-ubah lagi atau seimbang. Dengan menggunakan alat bantu yaitu software WinQSB versi 2.0, maka diperoleh hasil dari perhitungan perkalian matriks yang dapat dilihat pada Tabel 8 berikut ini:

Tabel 8. Probabilitas Pangsa Pasar Bagi Pengguna Satu Kartu GSM

\begin{tabular}{|c|c|c|c|c|c|c|c|}
\hline $\begin{array}{c}\text { Pangsa } \\
\text { Pasar } \\
\begin{array}{c}\text { Period } \\
\text { e ke- }\end{array}\end{array}$ & $\mathbf{A}$ & $\mathbf{B}$ & $\mathbf{C}$ & $\mathbf{D}$ & $\mathbf{E}$ & $\mathbf{F}$ & $\mathbf{G}$ \\
\cline { 2 - 9 } & & & & & & & \\
\hline 0 & 0,145 & 0,289 & 0,181 & 0,229 & 0,036 & 0,096 & 0,024 \\
\hline 1 & 0,133 & 0,325 & 0,120 & 0,181 & 0,000 & 0,084 & 0,157 \\
\hline 2 & 0,180 & 0,296 & 0,077 & 0,159 & 0,000 & 0,074 & 0,213 \\
\hline 3 & 0,212 & 0,264 & 0,078 & 0,143 & 0,000 & 0,069 & 0,233 \\
\hline 4 & 0,230 & 0,249 & 0,085 & 0,135 & 0,000 & 0,067 & 0,234 \\
\hline 5 & 0,237 & 0,244 & 0,090 & 0,131 & 0,000 & 0,068 & 0,230 \\
\hline 6 & 0,238 & 0,244 & 0,093 & 0,131 & 0,000 & 0,068 & 0,227 \\
\hline 7 & 0,237 & 0,245 & 0,093 & 0,131 & 0,000 & 0,069 & 0,225 \\
\hline 8 & 0,236 & 0,246 & 0,093 & 0,131 & 0,000 & 0,069 & 0,224 \\
\hline $\mathbf{9}$ & $\mathbf{0 , 2 3 5}$ & $\mathbf{0 , 2 4 6}$ & $\mathbf{0 , 0 9 3}$ & $\mathbf{0 , 1 3 2}$ & $\mathbf{0 , 0 0 0}$ & $\mathbf{0 , 0 6 9}$ & $\mathbf{0 , 2 2 4}$ \\
\hline 10 & 0,235 & 0,246 & 0,093 & 0,132 & 0,000 & 0,069 & 0,224 \\
\hline 11 & 0,235 & 0,246 & 0,093 & 0,132 & 0,000 & 0,069 & 0,224 \\
\hline 12 & 0,235 & 0,246 & 0,093 & 0,132 & 0,000 & 0,069 & 0,224 \\
\hline 13 & 0,235 & 0,246 & 0,093 & 0,132 & 0,000 & 0,069 & 0,224 \\
\hline 14 & 0,235 & 0,246 & 0,093 & 0,132 & 0,000 & 0,069 & 0,224 \\
\hline 15 & 0,235 & 0,246 & 0,093 & 0,132 & 0,000 & 0,069 & 0,224 \\
\hline 16 & 0,235 & 0,246 & 0,093 & 0,132 & 0,000 & 0,069 & 0,224 \\
\hline 17 & 0,235 & 0,246 & 0,093 & 0,132 & 0,000 & 0,069 & 0,224 \\
\hline
\end{tabular}

Sumber Data Primer; Diolah 2017

Keterangan: $\mathrm{A}=\mathrm{As} ; \mathrm{B}=$ Simpati; $\mathrm{C}=\mathrm{XL} ; \mathrm{D}=\mathrm{IM} 3$; $\mathrm{E}=$ Mentari; $\mathrm{F}=$ Three; $\mathrm{G}=\mathrm{AXIS}$

Berdasarkan Tabel 8 diperoleh nilai steady state yang dicapai pada peiode ke-9. Persentase nilai ekuilibrium masing-masing kartu GSM adalah sebagai berikut: kartu GSM As 24\%, kartu GSM Simpati 25\%, kartu GSM XL 9\%, kartu GSM IM3 13\%, kartu GSM Three 7\%, serta katru GSM Axis sebesar 22\%. Dengan demikian terlihat bahwa meskipun pangsa pasar kartu GSM As mengalami kenaikan dan penurunan pada awal-awal periode, tetapi pada akhirnya berhenti pada periode ke-9 yaitu pada 
angka 24\% ketika kartu GSM tersebut mencapai kondisi ekuilibrium. Demikian juga halnya dengan pangsa pasar untuk kartu GSM Simpati, XL, IM3, Mentari, Three, dan Axis yang mengalami kenaikan dan penurunan pada awal periode, namun nilainya akan tetap atau stabil setelah mencapai kondisi ekuilibrium.

\section{Pangsa Pasar Penggunaan Telepon dan SMS bagi Pengguna Dua Kartu GSM}

\begin{tabular}{|c|c|c|c|c|c|c|}
\hline \multicolumn{7}{|c|}{ pangsa pasar $=Y \times Y_{0}$} \\
\hline$[0,370$ & 0,243 & 0,222 & 0,000 & 0,000 & 0,250 & $0,333]$ \\
\hline 0,185 & 0,270 & 0,111 & 0,384 & 0,500 & 0,500 & 0,000 \\
\hline 0,037 & 0,108 & 0,333 & 0,076 & 0,000 & 0,250 & 0,000 \\
\hline 0,185 & 0,162 & 0,111 & 0,461 & 0,000 & 0,000 & 0,000 \\
\hline 0,037 & 0,027 & 0,000 & 0,000 & 0,000 & 0,000 & 0,000 \\
\hline 0,037 & 0,054 & 0,000 & 0,076 & 0,250 & 0,000 & 0,000 \\
\hline $\begin{array}{c}\mathrm{L} 0,148 \\
\ulcorner 0,278\end{array}$ & $\begin{array}{r}0,135 \\
\Gamma 0,2\end{array}$ & $\begin{array}{l}0,222 \\
7\end{array}$ & 0,000 & 0,250 & 0,000 & $0,667]$ \\
\hline 0,381 & 0,2 & & & & & \\
\hline 0,092 & 0,1 & & & & & \\
\hline 0,134 & $=0,1$ & & & & & \\
\hline 0,041 & 0,0 & & & & & \\
\hline 0,041 & 0,0 & & & & & \\
\hline$-0,031$ & $\mathrm{~L}_{0,1}$ & & & & & \\
\hline
\end{tabular}

Dari hasil perhitungan diatas terlihat bahwa untuk penggunaan telepon dan SMS bagi pengguna dua kartu GSM pada periode ke-1 kartu GSM Simpati menempati pangsa pasar tertinggi dengan persentase sebesar $26 \%$, diikuti posisi kedua ditempati oleh kartu GSM As dengan persentase sebesar 24\%, posisi ketiga ditempati oleh kartu GSM IM3 dengan persentase sebesar 19\%, diposisi keempat ditempati oleh kartu GSM Axis dengan persentase sebesar $14 \%$, posisi kelima ditempati oleh kartu GSM XL dengan persentase sebesar $10 \%$, posisi keenam ditempati oleh kartu GSM Tree dengan persentase sebesar $5 \%$, dan posisi terakhir ditempati oleh kartu GSM Treedengan persentase sebesar $2 \%$.

Dengan menggunakan cara yang sama maka akan diperoleh kemungkinan market share pada waktu mendatang, yang terlihat pada Tabel 9.

Kesimpulan dari Tabel 9 yaitu kondisi steady state tercapai pada periode ke-13. Persentase nilai ekuilibrium masing-masing kartu prabayar GSM adalah sebagai berikut: As $25 \%$, Simpati 20\%, XL 8\%, IM3 13\%, Mentari $2 \%$, Three $4 \%$, dan Axis $26 \%$.
Tabel 9. Probabilitas Pangsa Pasar Bagi Penggunaan Telepon dan SMS (bagi Pengguna Dua Kartu GSM)

\begin{tabular}{|c|c|c|c|c|c|c|c|}
\hline \multirow{2}{*}{$\begin{array}{c}\text { Pangsa } \\
\text { Pasar } \\
\text { Periode } \\
\text { ke- }\end{array}$} & \multicolumn{7}{|c|}{ Merek Kartu GSM } \\
\hline & $\mathbf{A}$ & B & $\mathbf{C}$ & D & $\mathbf{E}$ & $\mathbf{F}$ & $\mathbf{G}$ \\
\hline 0 & 0,278 & 0,381 & 0,092 & 0,134 & 0,041 & 0,041 & 0,031 \\
\hline 1 & 0,237 & 0,258 & 0,103 & 0,186 & 0,021 & 0,051 & 0,144 \\
\hline 2 & 0,234 & 0,233 & 0,098 & 0,159 & 0,016 & 0,042 & 0,194 \\
\hline 3 & 0,240 & 0,217 & 0,091 & 0,143 & 0,015 & 0,039 & 0,221 \\
\hline 4 & 0,245 & 0,208 & 0,086 & 0,135 & 0,015 & 0,038 & 0,236 \\
\hline 5 & 0,249 & 0,204 & 0,083 & 0,131 & 0,015 & 0,037 & 0,245 \\
\hline 6 & 0,251 & 0,201 & 0,081 & 0,131 & 0,015 & 0,037 & 0,249 \\
\hline 7 & 0,252 & 0,200 & 0,080 & 0,131 & 0,015 & 0,036 & 0,252 \\
\hline 8 & 0,253 & 0,199 & 0,079 & 0,131 & 0,015 & 0,036 & 0,254 \\
\hline 9 & 0,253 & 0,198 & 0,079 & 0,132 & 0,015 & 0,036 & 0,255 \\
\hline 10 & 0,254 & 0,198 & 0,079 & 0,132 & 0,015 & 0,036 & 0,255 \\
\hline 11 & 0,254 & 0,198 & 0,078 & 0,132 & 0,015 & 0,036 & 0,255 \\
\hline 12 & 0,254 & 0,198 & 0,078 & 0,132 & 0,015 & 0,036 & 0,255 \\
\hline 13 & 0,254 & 0,198 & 0,078 & 0,132 & 0,015 & 0,036 & 0,256 \\
\hline 14 & 0,254 & 0,198 & 0,078 & 0,132 & 0,015 & 0,036 & 0,256 \\
\hline 15 & 0,254 & 0,198 & 0,078 & 0,132 & 0,015 & 0,036 & 0,256 \\
\hline 16 & 0,254 & 0,198 & 0,078 & 0,132 & 0,015 & 0,036 & 0,256 \\
\hline 17 & 0,254 & 0,198 & 0,078 & 0,132 & 0,015 & 0,036 & 0,256 \\
\hline 18 & 0,254 & 0,198 & 0,078 & 0,132 & 0,015 & 0,036 & 0,256 \\
\hline 19 & 0,254 & 0,198 & 0,078 & 0,132 & 0,015 & 0,036 & 0,256 \\
\hline 20 & 0,254 & 0,198 & 0,078 & 0,132 & 0,015 & 0,036 & 0,256 \\
\hline \multicolumn{8}{|c|}{ Sumber Data Primer; Diolah 2017} \\
\hline
\end{tabular}

\section{Pangsa Pasar Penggunaan Internet bagi Pengguna Dua Kartu GSM}

pangsa pasar $=Z \times Z_{0}$
$\left[\begin{array}{lllllll}0,111 & 0,000 & 0,000 & 0,000 & 0,000 & 0,000 & 0,333 \\ 0,259 & 0,135 & 0,333 & 0,230 & 0,000 & 0,250 & 0,000 \\ 0,185 & 0,324 & 0,222 & 0,076 & 0,250 & 0,500 & 0,333 \\ 0,185 & 0,243 & 0,111 & 0,153 & 0,500 & 0,000 & 0,000 \\ 0,000 & 0,000 & 0,000 & 0,000 & 0,000 & 0,000 & 0,000 \\ 0,111 & 0,108 & 0,111 & 0,076 & 0,250 & 0,250 & 0,333 \\ 0,148 & 0,189 & 0,222 & 0,461 & 0,000 & 0,000 & 0,000\end{array}\right] \times$
$\left[\begin{array}{l}0,278 \\ 0,381 \\ 0,092 \\ 0,134 \\ 0,041 \\ 0,041 \\ 0,031\end{array}\right]=\left[\begin{array}{l}0,041 \\ 0,196 \\ 0,247 \\ 0,196 \\ 0,000 \\ 0,124 \\ 0,196\end{array}\right]$

Berdasarkan hasil perhitungan tersebut terlihat bahwa pada periode ke-1 untuk penggunaan internet bagi pengguna dua kartu GSM, kartu XL menempati pangsa pasar tertinggi dengan persentase sebesar $25 \%$, diikuti posisi kedua ditempati oleh kartu GSM Simpati, IM3, dan Axis dengan persentase sebesar 20\%, posisi ketiga ditempati oleh kartu GSM Tree dengan persentase sebesar 12\%, diposisi keempat ditempati oleh kartu GSM As dengan persentase sebesar 4\%, dan posisi terakhir ditempati oleh kartu GSM Mentari dengan 
persentase sebesar $0 \%$.

Dengan menggunakan cara yang sama maka akan diperoleh kemungkinan pangsa pasar (market share) pada waktu mendatang, yang terlihat pada Tabel 10 berikut:

Tabel 10. Probabilitas Pangsa Pasar Bagi Penggunaan Internet (Bagi Pengguna Dua Kartu GSM)

\begin{tabular}{|c|c|c|c|c|c|c|c|}
\hline $\begin{array}{c}\text { Pangsa } \\
\text { Pasar } \\
\begin{array}{c}\text { Periode } \\
\text { ke- }\end{array}\end{array}$ & $\mathbf{A}$ & $\mathbf{B}$ & $\mathbf{C}$ & $\mathbf{D}$ & $\mathbf{E}$ & $\mathbf{F}$ & $\mathbf{G}$ \\
\cline { 2 - 8 } & & & & & & & \\
\hline 0 & 0,278 & 0,381 & 0,092 & 0,134 & 0,041 & 0,041 & 0,031 \\
\hline 1 & 0,041 & 0,196 & 0,247 & 0,196 & 0,000 & 0,124 & 0,196 \\
\hline 2 & 0,070 & 0,196 & 0,268 & 0,113 & 0,000 & 0,165 & 0,189 \\
\hline 3 & 0,071 & 0,202 & 0,290 & 0,108 & 0,000 & 0,171 & 0,159 \\
\hline 4 & 0,061 & 0,210 & 0,290 & 0,111 & 0,000 & 0,166 & 0,163 \\
\hline $\mathbf{5}$ & $\mathbf{0 , 0 6 1}$ & $\mathbf{0 , 2 0 8}$ & $\mathbf{0 , 2 8 9}$ & $\mathbf{0 , 1 1 1}$ & $\mathbf{0 , 0 0 0}$ & $\mathbf{0 , 1 6 6}$ & $\mathbf{0 , 1 6 4}$ \\
\hline 6 & 0,061 & 0,208 & 0,289 & 0,111 & 0,000 & 0,166 & 0,164 \\
\hline 7 & 0,061 & 0,208 & 0,289 & 0,111 & 0,000 & 0,166 & 0,164 \\
\hline 8 & 0,061 & 0,208 & 0,289 & 0,111 & 0,000 & 0,166 & 0,164 \\
\hline 9 & 0,061 & 0,208 & 0,289 & 0,111 & 0,000 & 0,166 & 0,164 \\
\hline 10 & 0,061 & 0,208 & 0,289 & 0,111 & 0,000 & 0,166 & 0,164 \\
\hline 11 & 0,061 & 0,208 & 0,289 & 0,111 & 0,000 & 0,166 & 0,164 \\
\hline 12 & 0,061 & 0,208 & 0,289 & 0,111 & 0,000 & 0,166 & 0,164 \\
\hline 13 & 0,061 & 0,208 & 0,289 & 0,111 & 0,000 & 0,166 & 0,164 \\
\hline 14 & 0,061 & 0,208 & 0,289 & 0,111 & 0,000 & 0,166 & 0,164 \\
\hline
\end{tabular}

Sumber Data Primer; Diolah 2017

Keterangan: $\mathrm{A}=\mathrm{As} ; \mathrm{B}=$ Simpati; $\mathrm{C}=\mathrm{XL} ; \mathrm{D}=\mathrm{IM} 3$; $\mathrm{E}=$ Mentari; $\mathrm{F}=$ Three; $\mathrm{G}=\mathrm{AXIS}$

Dari Tabel 10 dapat disimpulkan bahwa kondisi ekuilibrium tercapai pada periode ke-5. Persentase nilai ekuilibrium masing-masing kartu prabayar GSM adalah sebagai berikut: As 6\%, Simpati 21\%, XL 29\%, IM3 11\%, Mentari $0 \%$, Three $17 \%$, dan Axis $16 \%$.

Dengan adanya informasi tentang nilai probabilitas masing-masing pangsa pasar tersebut maka perusahaan telekomunnikasi dapat menilai posisi perusahaan dan pesaingnya di pasar, serta perusahan mendapat gambaran atau informasi tentang kekuatan masing-masing perusahaan dalam mempertahankan atau mendapatkan pelanggan, sehingga informasi tersebut dapat dijadikan sebagai strategi pemasaran.

\section{SIMPULAN DAN SARAN}

\section{A. Simpulan Penelitian}

Dari penelitian yang telah dilakukan, maka dapat ditarik beberapa kesimpulan yang dipaparkan sebagai berikut:

1. Langkah pemodelan untuk perpindahan yang dilakukan oleh konsumen dengan menggunakan analisis rantai Markov, pertama yaitu menghitung jumlah pelanggan untuk masing-masing kartu GSM untuk periode ke-0 dan periode ke-1, selanjutnya menghitung perubahan merek dalam kurun waktu satu tahun yaitu dengan menghitung jumlah pertambahan dan pengurangan merek dalam kurun waktu satu tahun, menyusun matriks probabilitas transisi yang digunakan untuk menggambarkan rantai Markov tentang kegiatan pemilihan merek dan peramalan probabilitas transisi yang kemungkinan dilakukan oleh para konsumen, yaitu pergantian dari suatu merek ke merek lainnya. Menghitung peluang transisi pelanggan yang tetap loyal.

2. Pada perpindahan penggunaan satu kartu GSM dapat disimpulkan bahwa kondisi ekuilibrium (steady state) tercapai pada periode ke-9 dengan persentase pangsa pasar masing-masing merek kartu GSM sebagai berikut: As 24\%, Simpati 25\%, XL 9\%, IM3 13\%, Mentari 0\%, Three 7\%, dan Axis $22 \%$.

3. Pada perpindahan penggunaan merek kartu GSM bagi pengguna dua kartu GSM diperoleh dua kemungkinan nilai probabilitas pangsa pasar saat mencapai kondisi ekuilibrium yaitu:

- Perpindahan penggunaan telepon dan SMS mencapai kondisi ekuilibrium (steady state) pada periode ke-13 dengan persentase masing-masing kartu GSM sebagai berikut: As 25\%, Simpati 20\%, XL 8\%, IM3 16\%, Mentari 2\%, Three 4\%, dan Axis $26 \%$.

- Perpindahan penggunaan internet mencapai kondisi ekuilibrium (steady state) pada periode ke-5 dengan persentase masing-masing kartu GSM sebagai berikut: As 6\%, Simpati 21\%, XL 29\%, IM3 11\%, Mentari 0\%, Three 17\%, dan Axis $16 \%$. 


\section{B. Saran}

Adapun saran yang dapat diberikan penulis adalah bagi pengguna satu kartu GSM didapat bahwa kondisi ekuilibrium (steady state) tercapai pada periode ke-9 dengan persentase pangsa pasar masing-masing merek kartu GSM sebagai berikut: As 24\%, Simpati 25\%, XL 9\%, IM3 13\%, Mentari 0\%, Three 7\%, dan Axis $22 \%$ sehingga perusahaan telekomunikasi dapat mempersiapkan strategi apa saja yang dapat ditawarkan kepada pelanggan sehingga tidak kehilangan pelanggan diperiode mendatang. begitu juga untuk pengguna dua kartu GSM.

\section{Daftar Pustaka}

Subagyo, P., Marwan, M., T., Handoko T.H.. 1999, Dasar-Dasar Operations Research. Edisi Kedua. Yogyakarta: BPFE.

Aswin, R. 2010. Penentuan Peluang Transisi t Langkah Dalam Rantai Markov dan Penerapannya di Bidang Pertanian. Skripsi Departemen Matematika FMIPA Universitas Sumatera Utara. Medan.

Surachman dan Astuti, M. 2015. Operations Research. Edisi Kedua. Malang: Media Nusa Creative.

Yakub, R. 2008. Dinamika Pada Rantai Markov dengan Dua Komponen. Skripsi Fakultas Matematika dan Ilmu Pengetahuan Alam Universitas Sumatera Utara. Medan. 